\title{
Hamartoma of the thoracic wall
}

\author{
SAIBAL GUPTA and NARAYAN C. PAL \\ Department of Thoracic and Cardiovascular Surgery and Department of Pathology, \\ Institute of Postgraduate Medical Education and Research, Calcutta 20, India
}

\begin{abstract}
A 16-year-old boy presented with a slowly growing tumour of the chest wall involving the posterior ends of the second and third ribs on the left side and the corresponding vertebrae. The tumour on excision was a well-localized growth with a bony shell, the second and third ribs originating from its anterior end. Histological studies showed a benign tumour with haphazard distribution of bony spicules, smooth muscle, adipose tissue, angiomatous tissue, nerve bundles, and lymph follicles. This was diagnosed as a hamartoma of the thoracic wall.
\end{abstract}

Hamartoma has been described in many organs and tissues of the body. The most important from the point of view of the chest surgeon is the pulmonary hamartoma. Its character, behaviour and variations have been widely reviewed (Bateson, 1965; Oldham, Young, and Sealy, 1967). But, so far as we are aware, there is no reference in the world literature to hamartomal growths of the thoracic wall. One case that has been operated and studied is presented here with the diagnosis of hamartoma of the thoracic wall.

\section{CASE REPORT}

P.N.R., a boy aged 16 years, came to the neurosurgery outpatient department in a peripheral area complaining of pain and burning sensation in the left side of the chest, left shoulder, and left arm starting insidiously about six years previously. He had also noticed excessive sweating in the left armpit and left palm and progressive deformity of the left chest. The shoulder pain got worse with movement of the neck and abduction of the arm. The patient was ultimately referred to the thoracic surgery unit.

On examination he showed normal growth and development. The striking feature was a marked scoliosis of the upper part of the dorsal spine with convexity towards the right. The left shoulder was short and there was a prominence in the infraclavicular region of the left chest. Compensatory curvature of the cervical spine produced a tilting of the head.

A radiograph of the chest and spine (Fig. 1) showed a soft tissue shadow, with mottled calcified areas, destroying the second and third ribs and pressing and flattening the first and fourth ribs. There was also destruction of the pedicle, laminae, and vertebral bodies on the left side of the corresponding dorsal vertebrae, most marked in D2 and D3, with scoliosis.

Aortic arch angiography was done and a selective angiogram of the soft tissue mass was first obtained through an intercostal artery. This showed the presence of numerous irregular vascular spaces within the mass. The regular arch angiography showed that the mass did not have excessive vascular connexions.

The patient was operated on 13 May 1970 and the mass was explored. A posterolateral approach was undertaken, mobilizing the scapula as in a thoracoplasty. The scapular muscles were adherent to the superficial aspects of the tumour which produced a slight fleshy bulge above the rest of the chest wall without excessive vascularity. The scapula was mobilized by dividing these muscle bands. The deformed fourth rib was then removed to give a little more space, and the pleural cavity was entered. The parietal pleura was intact and the mass was wholly extrapleural. The left lung was free and the consistency of the tumour was bony hard. The tumour was then detached from the under surface of the first rib subperiosteally and the anterior ends of the remnants of the second and third ribs were divided. The rest of the tumour came out surprisingly easily from the side of the eroded vertebral column and surrounding tissues. Two normalsized intercostal arteries were the only feeding vessels and they were ligated and divided. The second and third dorsal vertebrae were so eroded that the dura was visible. It had been closely applied to the posterior end of the tumour and was uninjured following separation of the tumour. The defect in the chest wall was bridged by suturing remnants of pleura and intercostal muscles and flaps of surrounding soft tissue and the wound was closed in layers leaving an intercostal drain in the pleural cavity. The patient made an uncomplicated recovery and was sent home within two weeks.

MICROSCOPIC DESCRIPTION The tumour was ovoid, about $8 \times 6 \mathrm{~cm}$ in size. It was wholly extrapleural. The surface was a bony shell which was deficient at one place on the outer surface. From the anterior aspect of the tumour portions of two ribs were jutting out. 


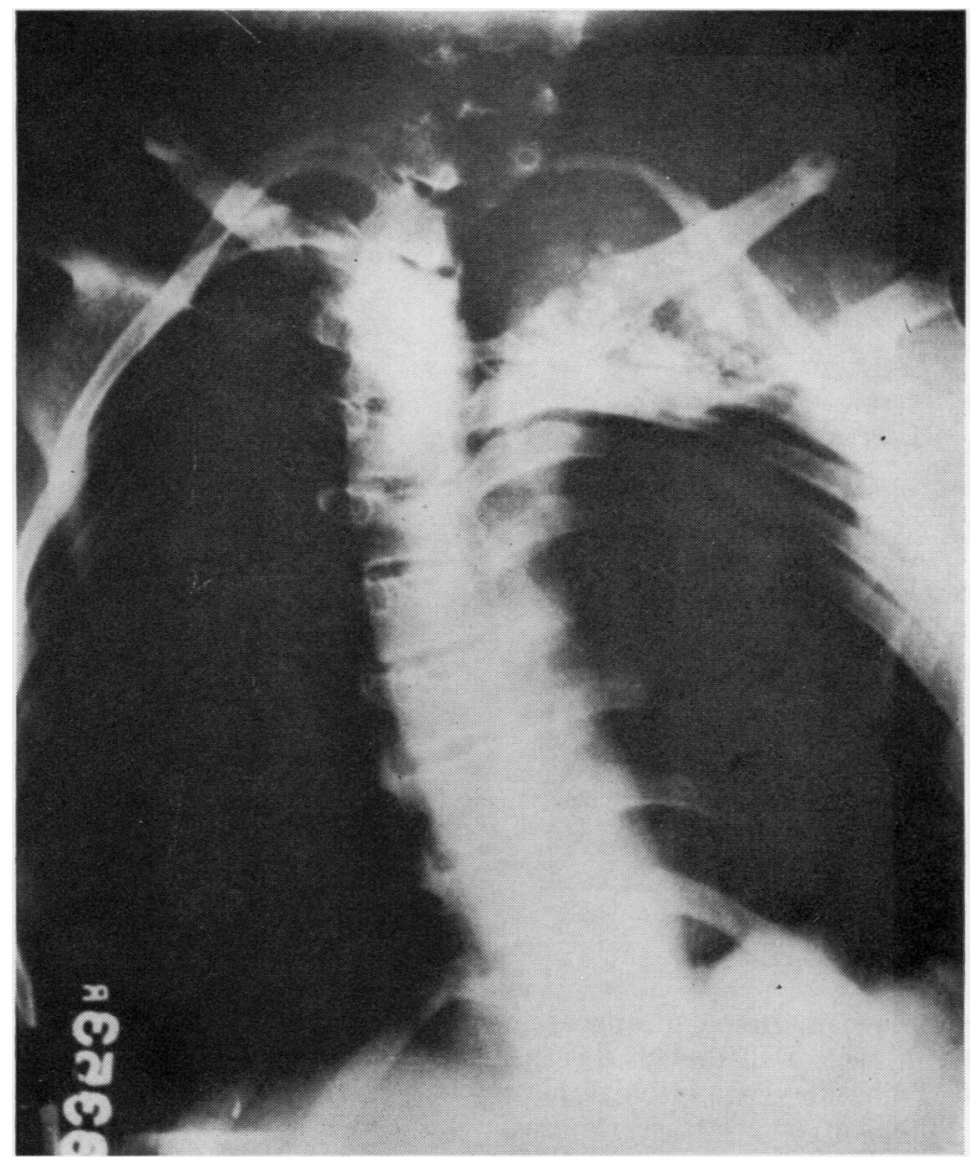

FIG. 1. Straight radiograph of chest and spine showing the tumour mass (for description see text).

There were no posterior ends of the ribs and the posterior end of the tumour was rounded like an egg. The cut surface of the tumour showed a firm variegated appearance with bony spicules, calcified areas, and numerous vascular spaces.

HISTOPATHOLOGY The histology of the tumour was studied by taking sections from different areas. The sections showed a variegated appearance with tissues of different types intermingled without any definite pattern. The predominating histological picture was that of angiomatous tissue of various types showing both capillary and cavernomatous patterns.

The other interesting findings in this tumour mass were a mixture of smooth muscle and adipose tissue (Fig. 2); bony spicules along with the angiomatous and fibrous tissues (Fig. 3); a well-defined lymphoid follicle; and well-defined nerve bundles with angiomatous tissue. Because of the presence of such varied types of tissue without a definite pattern inside a well-circumscribed mass, the tumour was diagnosed as a hamartoma.
FOLLOW-UP

The patient has been followed up for one year. On 10 May 1971, the patient had no subjective symptoms. There were no signs of recurrence. The scoliosis persists and shows no sign of improvement. The chest radiograph was normal apart from two absent ribs and scoliosis.

\section{DISCUSSION}

The term hamartoma was first used by Albrecht in 1904 to refer to a congenital abnormal mixing of the normal components of an organ. Hart (1906) was the first to give this name to the pulmonary tumours which had been described even earlier. Hamartomas have been described in most organs and tissues of the human body (Willis, 1967). It is 


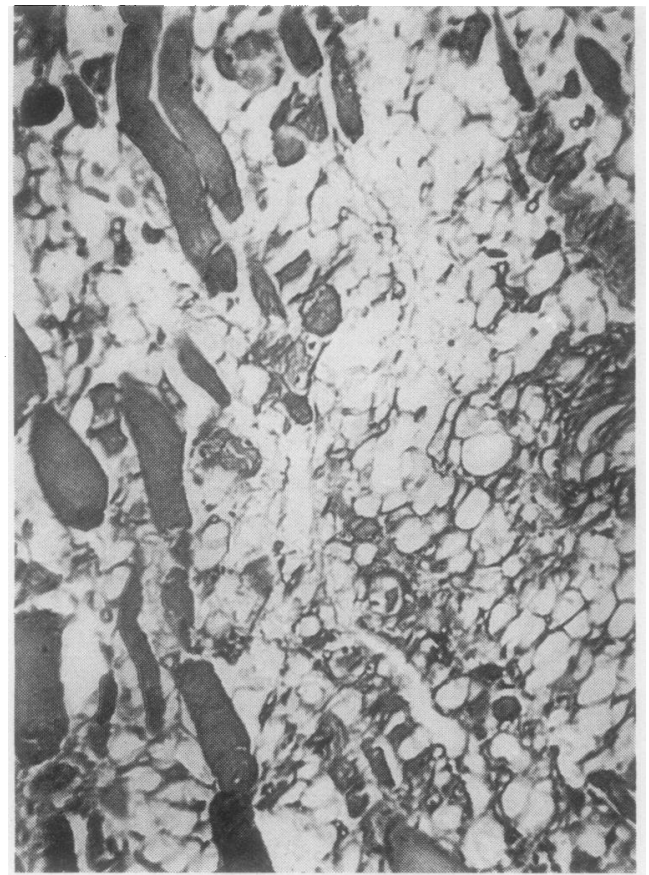

FIG. 2. Smooth muscle and adipose tissue (H. \& E. ×210).

therefore possible for a hamartoma to appear in the musculoskeletel thoracic wall though this has not been reported. Pulmonary hamartomas have been found as subpleural growths (Matras, 1929 ; Oldham et al., 1967) or even as growths lying free in the pleural cavity (Lemon and Good, 1950). A tumour lying wholly extrapleurally with involvement of the vertebrae should be considered a growth from the thoracic wall rather than from pulmonary elements. The pathological diagnosis of the tumour as hamartoma rests on a well-circumscribed tumour of normal vascular supply involving two consecutive ribs and vertebrae and containing tissues of various types in a disorganized and bizarre fashion. This tumour is not a haemangioma in spite of the predominantly angiomatous tissues for two reasons: the presence of tissues of other types in many areas of the tumour and the well-circumscribed nature of the tumour without enlarged feeding vessels. This tumour has therefore been termed a hamartoma of the thoracic wall.

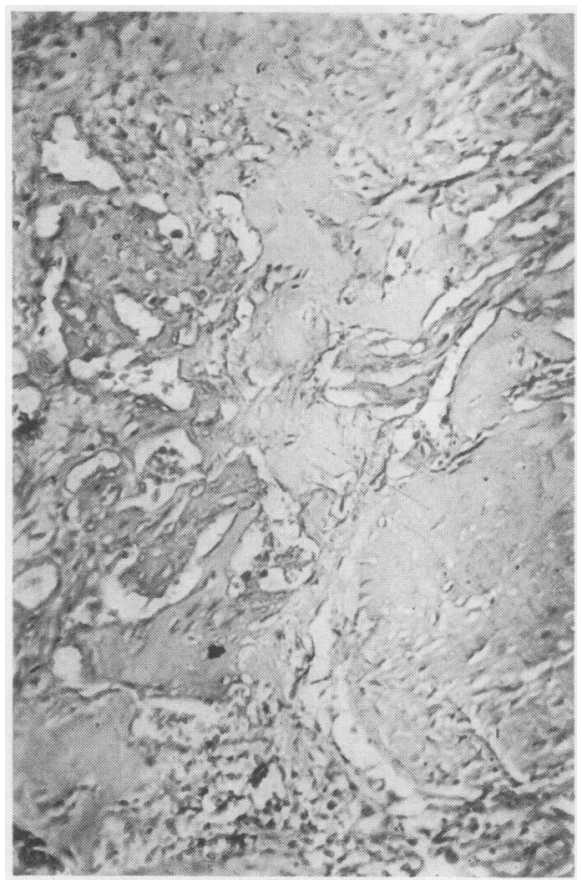

FIG. 3. A bony spicule with collagenous tissue and cavernous haemangioma $(H . \& E . \times 210)$.

We are grateful to Professor A. K. Mukherji, professor of orthopaedics, for referring this patient and to Professor K. C. Basu Mallick, director of the Institute, for permission to publish this report.

\section{REFERENCES}

Albrecht, E. (1904). Ueber Hamartome. Verh. dtsch. path. Ges., 7, 153.

Bateson, E. M. (1965). Relationship between intrapulmonary and endobronchial cartilage-containing tumours (socalled hamartomata). Thorax, 20, 447.

Hart, C. (1906). Ueber die primären Enchondrome der Lunge. $Z$. Krebsforsch., 4, 578.

Lemon, W. E., and Good, C. A. (1950). Hamartoma of the lung. Radiology, 55, 692.

Matras, A. (1929). Ueber ein Adenofibrochondrolipoma myxomatodes der Lunge. Wien. klin. Wschr., 42, 1369.

Oldham, H. N., Young, W. G., and Sealy, W. C. (1967). Hamartoma of the lung. J. thorac. cardiovasc. Surg., 53, 735.

Willis, R. A. (1967). Pathology of Tumours, 4th ed. Butterworths, London. 